\title{
A FORMAÇÃO DE ENFERMEIROS NO BRASIL NA DÉCADA DE $70^{1}$
}

\author{
THE EDUCATION OF NURSING WORKERS IN BRAZIL IN THE 1970'S \\ LAFORMACIÓN DE ENFERMEROS EN BRASIL EN LOS AÑOS 70
}

Lygia Paim²

RESUMO: Este artigo objetiva revisitar os anos 75-79 e com eles a história da implantação de novos cursos de graduação em Enfermagem em Universidades Federais e em Distritos Geo-educacionais que ainda não ofertavam esse tipo de curso. Apresenta-se a trajetória do desenvolvimento do Projeto de Enfermagem no Grupo Setorial de Saúde - SESU/DAU/MEC. Ressaltam-se determinantes políticosociais no aumento quanti-qualitativo intencional desses Cursos. Clarifica-se a proposta, processo e realizações envolvidas no Projeto Superior de Enfermagem, antes predominante como ensino privado (até 1974), para predominantemente ensino público (1976). Ademais, aponta implicações tais como: Comissão de Especialistas do Ensino de Enfermagem (CEEEnfermagem) articulada à ABEn e a primeira proposta coletiva de Áreas e Linhas de Pesquisa em Enfermagem (CNPq/CAPES/ DAU/ABEn, bem como a iniciação de espaços intitucionalizados nesses Órgãos de formação e atração acadêmica.

PALAVRAS-CHAVE: história, educação em enfermagem, ABEn

A memória "carregada por grupos vivos" (Nora, 1993), vem ressignificar as experiências vividas nos anos 1975 - 1979, no serrado em Brasília - DF, quando, alguns enfermeiros tornaramse membros integrantes de um dos Grupos Assessores que na ocasião se compunham no então Departamento de Assuntos Universitários do Ministério da Educação e Cultura (DAU/ MEC). Ao buscar a ressignificação dessas experiências vividas, a realidade de hoje faz tudo renascer; é como se fossem momentos mágicos, criando um elo entre o presente e o passado, tudo tão tônico como uma força invisivel a puxar os fios da meada, desatá-los, de modo a se perceber que há uma história viva a "expor (os gestos), os silêncios e as deficiências da documentação escrita." ( Samuel, 1990)

Esforço-me por deixar fluir esses momentos mágicos com a lucidez possivel, para desembaraçar os fios, numa interpretação de quem carrega consigo a história de muitos, guardada nas fotos animadas em álbum que, ao ser folheado, espalha luzes em retrovisão do tempo e lugar, um dia habitado profissionalmente, e agora, mais que antes, desocultando momentos expressivos de significado social. São fotos de pessoas, algumas cartas, são escritos pessoais, ou mesmo algum objeto guardado, muito além de documentos oficiais ou publicações, estas tão raras à época, mas também existentes, puxando, de cada imagem, novas memórias, as quais, por certo acompanham a vida daqueles que se envolveram e presenciaram esse capítulo da história, delineada no cenário da Educação de Enfermagem, no Brasil dos anos 70.

O cenário desse Brasil dos anos 70 teve então numa única década duas margens, uma definida pelo Al-5 de 1968 manchando a sua primeira metade, quando estava em plena vigência o rigor do regime político militar e, outra, demarcada pela extinção da formalidade do Al-5, vinda do comando presidencial, entendida como "dar uma trégua ao excessivo rigor engendrado pela ditadura militar reinante", o que foi exposto à sociedade civil como proposta de "abertura lenta,

${ }^{1}$ Artigo escrito por solicitação da ABEn - Revista Brasileira de Enfermagem - na Comemoração dos 75 anos ABEn-2001.

2 Prof Titular (Aposentada) da EE. Ana Neri-UFRJ. Profi Colaboradora da Pós-Graduação do Depto. De Enfermagem - UFSC. Prof do Curso de Graduação em Enfermagem da UNISUL Campus Pedra Branca - Fpolis - SC. 
gradual e segura" (Aquino, 2000).

Foi em meio a essa trégua, que o DAU/MEC tomou a iniciativa de fazer a composição de um Grupo Setorial de Saúde (GSS). Tal grupo foi considerado como assessoria, diante das questões sociais de formação em saúde e suas correspondentes implicações. O propósito assumido pelos integrantes desse grupo convergia em criar possibilidades democratizantes na educação, focalizadas na ampliação de vagas, de cursos e, em simultâneas providências, para fomentar mais qualidade no ensino superior, nas diversas áreas profissionais da Saúde.

O G.S.S. foi, então, coordenado por educador que dava visibilidade e decodificava como próprio grupo, as questões sociais implicadas, predominantemente, com uma ou com outra dessas áreas profissionais, não vistas isoladamente, mas considerando-as no conjunto das profissões de Saúde, em discussões e encaminhamentos nascidos na diversidade, na ótica das diferenças e no exercício do respeito à autonomia de argumentação e decisão dos vários segmentos ali representados, o que revertia em aprendizagem social continuada, até pelo exercício cotidiano de relacionamento saudável, interpessoal e interprofissional.

Eram alvissareiras as relações que hoje podem ser revisitadas como impávidas nos anos 70 , no cenário da Saúde, porquanto desaguavam no encontro entre saúde e movimentos sociais, o que, de modo ainda tênue, vinha se refazendo depois dos danos políticos desde 1964, em todo o pais. Refazer esse encontro dependia, inclusive, de que os profissionais de Saúde nutrissem sua força político-social e respondessem criticamente às situações que lhes eram pertinentes no contexto ainda em reconstrução.

No mundo inteiro, o sofrimento humano causado pela crise econômico-social, se fazia manchete; as populações anseavam por saídas e os projetos nascentes no Brasil, na década de 70 , buscavam uma outra lógica, tanto para a educação em saúde como para o exercício dos profissionais desse Setor de Serviços; insinuava-se uma lógica, que respondesse aos desafios que se colocaram posteriores ao rompimento dos direitos humanos, em seus princípios universais de justiça, eqüidade, exigindo novos olhares aos sistemas de saúde e de educação, quanto a acessos, qualidade, e ações básicas, vislumbrando a promoção da saúde.

Havia acenos de que até para eliminar a dura verticalidade vivida, o caminho seria o do empenho na horizontalização das relações, seja entre profissionais e, entre estes e os usuários do sistema de saúde, como também no âmbito acadêmico, sobretudo fazendo resistência à exclusão, à desigualdade social. Ao mesmo tempo convivíamos confrontados com o aviltamento da medicalização e da desmedida importação e uso de equipamentos tecnológicos para o atendimento à saúde, a vez das multinacionais em lucros desmedidos.

Foi nesta $2^{a}$ metade dos anos 70 que também circulavam os textos de estudo, interpretação e movimentos em torno da Declaração de Alma Ata e a composição do ideário de Saúde para Todos. Por sua vez, já eram visibilisadas as bases e, em particular, a igreja católica liderava a retomada político-social a partir das questões de saúde.

Em 1975 com a promulgação da Lei do Sistema Nacional de Saúde (Lei 6229) é criado - Conselho de Desenvolvimento Social que coordenava as ações e situava-se além dos Ministérios. Com a V Conferência Nacional de Saúde foi definida a Política Nacional de Saúde e o PIASS passou a ser desenvolvido em alguns municípios. Em seguida, o tema que ocuparia centralidade vinha derivado de Alma Ata e concentrava-se em Serviços Básicos de Saúde, desembocando no Prev-Saúde, o Programa Nacional de Serviços Básicos de Saúde, e a grande mobilização proveniente da Medicina Preventiva e Social vem fortemente fazer emergir um movimento de reconceitualização da saúde-doença e dos estudos, de outros determinantes sociais, históricos, econômicos e políticos, ao adoecer, antes, unicamente, situado nos aspectos biológicos.

Nesse mesmo ano, 1979, estavam se formando as primeiras turmas de enfermeiros procedentes dos cursos de enfermagem, criados nas Universidades Federais, onde tais cursos ainda não existiam, nos anos 1975 e 1976. No fim dessa década de 70 também surgiram, com 
visibilidade, as primeiras pesquisas de enfermagem orientadas nessa dimensão do conhecimento de ciências sociais e nos anos 80 , no $\mathrm{CNPq}$ - há a participação de maior número de projetos, após um Encontro entre representantes deste Órgão de Pesquisa, o DAU/MEC/CAPES e a Comunidade Científica de Enfermagem, a quem foi apresentado o PBDCT - III Plano Básico de Desenvolvimento Científico e Tecnológico; esse Encontro foi realizado em articulação com a ABEn que sediou o evento e apoiou as dinâmicas, através do CEPEn. Pela primeira vez, no Brasil, a Enfermagem, organizou coletivamente um Documento Unificado sobre suas Linhas e Áreas de Pesquisa (CNPq, 1982).

Cenário montado, síntese de acontecimentos, segunda metade de 70, Saúde, enfermagem, todos... seguiamos, como a poesia "Sugestão" de Clarice Lispector "...igual à pedra detida/sustentando o seu demorado destino...", até que reacendesse o encorajamento e não tardasse a hora e o rumo que norteava a liberdade que estava dentro de cada um, dos grupos, do país.

Cabe agora deter o olhar no percurso e nele trazer à cena o andamento do processo de incremento ao ensino superior de Enfermagem nesse Brasil-70. Por certo, intencionalmente, precisa ser buscada a história deste capítulo da educação de enfermagem, em versões e interpretações que vão além dos espaços da estrita oficialidade. Valerá referir os sinais que esboçaram ameaçadores limiares vividos. Por vezes, apresentaram-se como resistência de frentes políticas conservadoras, endógenas, ensimesmadas da própria enfermagem; outras vezes, limiares vividos prazerosamente, como momentos de refrigério, ao ver insinuadas vanguardas, inquiridoras, críticas, participativas, centradas na construção do conhecimento social de saúde trabalhando e aprendendo em bases solidárias, desejosa de articulação mais justa e rítmica na organização de vida associativa, gente que esboçava a possibilidade de uma luta com esperança, gente que entendia a composição de uma Enfermagem com o reerguimento de nova história, rompendo com o menos amargo, compartilhando, dialogando e convivendo, de modo espraiado, com outros profissionais

O itinerário no roteiro da implantação dos "novos cursos-70", um ponto de partida. Esse espaço, aqui, chamado ponto de partida, tem como lugar o DAU/MEC, BSB, e ali, a chegada de três consultoras de enfermagem, "Três Marias". Eram três enfermeiras, docentes vindas de três escolas de enfermagem escolhidas dentre as mais antigas instituições de Ensino da Comunidade de enfermagem (uma da UFPe; outra da USP; e ainda outra da UFRJ); todas de regiões muito populosas e com liderança no ensino de enfermagem; além disso, o convite do DAU/MEC se fez a três profissionais que à época já tinham obtido suas respectivas titulações pós-graduadas (sentido estrito), no exterior e, as escolas, no Brasil, das quais faziam parte, ofereciam cursos de pós-graduação em enfermagem. Ademais, cada uma das "Três Marias", carregava a história de participações em diversas oportunidades de liderança e de exercer cargos da Enfermagem (Diretorias de Escolas, Vida associativa, Projetos Especiais em Enfermagem, Publicações, Pioneirismo em criação de Cursos, etc). Então, era um convite do DAU/MEC, não sem atentar para o perfil de expressão intelectual das profissionais convidadas a prestar consultoria.

O MEC iria constituir o Grupo Setorial de Saúde e solicitou das Universidades, uma representante enfermeira-docente, envolvida com a educação superior de enfermagem, e de resto, com as questões sociais imbricadas no Setor Saúde. Embora, cada área desse Grupo Setorial de Saúde (GSS) tivesse um diagnóstico do ensino superior que the correspondia, naquela consultoria prestada pelas "Três Marias" a pauta de Enfermagem teve início com a notícia insólita de que as estatísticas do MEC registravam a Enfermagem como a área do Ensino Superior que menos havia crescido nos últimos 20 anos (1953-1973).

Eram várias considerações desde as quantitativas de número de enfermeiros e necessidades da população, evocada à época, a vigência do Plano Decenal de Saúde para as Américas, com suas propostas preditivas de proporções estimadas entre número de enfermeiros 
e habitantes. Essas discussões esbarravam no quadro caótico de enfermeiros face a o pululante aumento de habitantes no Brasil. O referido plano estimava 4,5 enfermeiros por 10 mil habitantes. O Brasil tinha como população estimada para 1980 (5 anos depois da discussão), 125 milhões. As "Três Marias" tiveram acesso a um documento que um Grupo de Trabalho, constituído de enfermeiras, em 1964, apresentara ao então Ministro da Educação e Cultura. Nesse documento, estava escrito que "... a continuar o rítmo de crescimento de formados em curso superior de enfermagem, em 1980, o total de enfermeiros seria 17.650, o que significava um "déficit" de 38.600 enfermeiros, ou seja, dobrando o número de enfermeiros, estimado para 1980, ainda assim, no Brasil não se alcançaria a relação enfermeiro: habitante, proposta no Plano Decenal de Saúde para as Américas.

Dois outros argumentos em favor de empregar recursos para intensificar o crescimento quantitativo e qualitativo dos Cursos Superiores de Enfermagem se concentravam, primeiramente, na inexistência desses cursos de enfermagem em diversos distritos geo-educacionais, sobremodo aqueles mapeados nos extremos do pais, como por exemplo no Acre, outro exemplo em Rio Grande (RS), ou ainda na região central, como Goiás, Mato Grosso e, mesmo em Brasilia (onde nos anos 70 era incipiente a idéia de criação do Curso na UnB).

Depois, na distribuição dos cursos já existentes, que era extremamente concentrada e, o Sudeste, tinha o maior número deles. No entanto, o que mais chamou a atenção do GSS foi a menor participação federal na área de enfermagem (apenas 30\% dos Cursos de Enfermagem existentes, estavam subordinados à administração federal). Isto equivale a dizer que o ensino Superior de Enfermagem estava predominantemente situado em subordinação administrativa da área privada, (39\%, dos 36 Cursos existentes em 1975). Essas instituições que mantinham os Cursos de Enfermagem vinculados ao caráter particular, quase todas, eram de propriedade de grupos religiosos (MEC/DAU, 1978).

Diante disso, restava saber a quem teria interessado manter o privado, o particular, como a marca histórica dos Cursos Superiores de Enfermagem, desde os anos 50 até os anos 70 ? Estaria aí mais uma das implicações do que estava sendo chamado de menor crescimento dos Cursos Superiores de Enfermagem?

Nessa mesma Consultoria sobre o Ensino Superior de Enfermagem, as consultoras "Três Marias" discutiram no GSS, a questão de estrutura física (instalações e equipamentos) em sua maioria, estes eram recursos escassos e ultrapassados, carecendo de renovação, substituição, atualização. A centralidade do debate estava no investimento maciço para aumentar número de vagas nas escolas em Universidades Federais e que tivessem potencial e demanda, e, muito principalmente, investir na criação de cursos de enfermagem nas Universidades Federais que não contavam com esse tipo de curso, ou se fosse o caso, absorção, pela Universidade Federal, de curso já existente na região. A cobertura do Ensino Superior de Enfermagem pela rede federal precisava se dar, e assim inverter o quadro do Ensino Superior de Enfermagem, passando de predominantemente privado a predominantemente público, portanto, gratuito.

O segundo grande tópico, de discussão das "Três Marias" com o GSS, foi a adoção de uma política de qualidade voltada para a capacitação do pessoal envolvido no ensino superior de enfermagem, o que significava investir em cursos de Pós-Graduação (Mestrados e Doutorados) em Universidades Federais, além de manter especializações (pós-graduação sentido amplo), como ofertas regulares de Cursos para enfermeiros e enfermeiros-docentes.

Reconhecendo que as idéias decorrentes dessa Consultoria, constituidas agora em Documento intitulado "Situação de Enfermagem - 1975" dava lugar a um plano de trabalho do DAU/MEC, localizado no seu GSS.

Através de solicitações do MEC/DAU à UFRJ, duas enfermeiras-docentes do ensino Superior da Escola de Enfermagem, foram colocadas à disposição do MEC, a fim de que elas integrassem o GSS. Para isto, os Avisos Ministeriais foram os documentos oficiais que formalizaram o deslocamento dessas duas enfermeiras, que passaram a residir em Brasilia- 
DF, em 1976.

A questão do GSS no que diz respeito à Enfermagem, passava a ser, como implementar as ações demandadas do referido documento afetiva e respeitosamente sintetizado na familiaridade adquirida no trabalho, como o Documento das "Três Marias", lembrando uma constelação, pois na proposta feita pelas suas autoras, estava no sub-texto, rascunhada a confiança no crescimento de uma outra constelação de novos enfermeiros.

Quanto à especificidade de corrigir o quadro de não crescimento do ensino superior da enfermagem brasileira desde 1953, esta quando interpretada, se mostra paradoxal, já que em sua trajetória histórica desde o nascedouro, a enfermagem seguiu quase sempre em silenciosa e obediente fidelidade às prescrições de oficialidade governamental. Contudo, não há registro de lutas coletivas, para obter os recursos à prevenção desse declínio, estatisticamente demonstrado, numa acumulação histórica de, no mínimo, 20 anos sem crescimento.

Por outro lado, seria possivel entender esse quadro do ensino de enfermagem se outros cursos do ensino superior, apresentassem situação semelhante. Neste caso, há que se rememorar o desprezo às políticas sociais, em particular, as de Educação e de Saúde, justamente as que estão diretamente envolvidas na Ärea de Enfermagem. Quem sabe, esse alheiamento ao ensino e à assistência à saúde, por si só, pudesse explicar os 20 anos de retração do crescimento da formação de enfermeiros.

Por muitas vezes, no entanto, em 1976, neste Projeto, foi possivel perceber, com estranheza, o receio das enfermeiras quando se aventava a hipótese de aumentar vagas ou aumentar número de cursos de enfermagem no ensino superior. Por vezes, retraíam-se e outras vezes argumentavam, com certa irritabilidade, que o risco dessa expansão, era a desorganização, a dificuldade de controle, a fuga do padrão (referindo-se ao sistema disciplinar), entre outros temores.

De outro ângulo, as Universidades Federais que ainda não contavam com a oferta de Cursos Superiores de Enfermagem, mostravam-se animadoras, cheias de expectativa, apalavrando, desde os primeiros contatos, que fariam todo o esforço e empregariam toda a concentração de recursos, para desenhar o projeto dessa oferta de cursos. Para essas Universidades Federais, o DAU/MEC, reservava o máximo de atenção e criava facilidades para que o assessoramento técnico não faltasse durante todo o processo de implantação dos Cursos e, as exigências de qualidade fossem todas cumpridas em tempo hábil, até chegar à obtenção da autorização e reconhecimento desses Cursos, à época, função privativa do Conselho Federal de Educação-CFE atualmente, denominado Conselho Nacional de Educação-CNE.

Portanto, a enfermagem dentro do GSS no DAU/MEC, teria que a partir do Documento "Situação de Enfermagem-1975", elaborado pelas Consultoras "Três Marias" tomado como Documento Básico de Enfermagem, fazer os desdobramentos éticos, políticos, técnicos e sociais, bem como definir o plano de ação, já que os Cursos a serem implantados, estariam cobrindo todas as regiões do território nacional e adicionando 16 unidades a mais de Cursos de Graduação em Enfermagem nas Universidades Federais, cuja justificativa era de:

- alterar o quadro que revelava a situação de Ensino Superior de Enfermagem, no que diz respeito a dominância do ensino particular, e a intencionalidade de conseguir a dominância do ensino público, portanto, gratuito, já que havia Universidades Federais que ainda não ofertavam Cursos de Graduação em Enfermagem.

- investir recursos para apoiar o aumento do número de oferta de vagas no ensino Superior de Enfermagem, e, tão somente, em Universidades Federais com Cursos de Enfermagem já existentes além de, determinar um número máximo de vagas iniciais, nos Cursos Novos em Universidades Federais que iriam implantá-los.

- desestimular iniciativas de instituições que não fossem de subordinação administrativa pública - estimulando as federais, estaduais e municipais; guardados os critérios de qualidade previstos. 
- atentar para as implicações qualitativas que influenciavam as estatísticas de não crescimento da Enfermagem no Ensino Superior.

- familiarizar o CFE com essa iniciativa do Grupo Setorial de Saúde no DAU/MEC, encaminhando relatórios de acompanhamento de processos de criação desses Cursos em Universidades Federais - bem como, documentos produzidos sobre requisitos ou exigências prévias, ou ainda, critérios de qualidade para implantação de Cursos de Enfermagem. Com isto, reforçava-se o apoio e incentivo às Universidades Públicas e, de algum modo, o controle de qualidade estaria disponível como um limitante a abertura desordenada de outros novos cursos, simultaneamente, e fora do propósito do Projeto, no MEC.

Tais iniciativas, foram definitórias de um processo que se queria, intemerato. No DAU/ MEC, o Grupo Setorial de Saúde, conseguiu manter esse propósito e comprometeu-se com 16 Cursos Novos, em Universidades Federais, alguns deles, iniciados com extremas dificuldades, para conseguir fixar um Corpo Docente dentro das qualificações previstas no DAU/MEC, mas finalmente, foi possivel compor os Grupos Docentes, utilizando diligências tanto da própria Universidade como de parte de muitas consultoras que estimulavam alunos de pós-graduação a enfrentarem os desafios de participar da Docência nesses Cursos, em distanciamento de grandes centros, como era, por exemplo, a situação do Acre-Fundação Universidade Federal do Acre.

O GSS conseguiu influenciar o MEC que veio a tomar uma posição com a qual o CFE tornou-se de acordo e então, foi colocado um limite importante, no desconserto que, incipientemente, se instalava, por pressões esperadas em processos desse tipo, sujeitos a interpretações de conveniência a possibilidade de lucros econômicos.

Após algumas definições, o processo em si, requeria decisivas articulações e estas foram, intrepidamente, buscadas pelo GSS e tiveram que ser, o mais exaustivamente possivel, argumentadas, porém resultaram em significativos caminhos para reverter o quadro de crescimento do Ensino Superior de Enfermagem, diagnosticado quantitativamente, passando a vislumbrar um outro quadro, que se iniciava com preceitos vigentes apropriados a um crescimento qualificativo, indo além da proposta de quantificação e melhor distribuição dos cursos superiores de enfermagem, no pais.

Tendo em conta que até 1975, o Corpo Docente do conjunto de todos os Cursos Superiores de Enfermagem contava com, apenas, 9,5\% de titulados, sendo Mestres (5,5\%) e Doutores (4\%), embora houvesse 3\% com o título de Livre-Docente, num total de 12,5\%, estes percentuais, do ponto de vista da qualificação por pós-graduação estrito senso, Mestrado e Doutorado, eram mínimos e, por certo, influenciaram as estatísticas relativas ao crescimento, no diagnóstico dos Cursos Superiores de Enfermagem, a que se refere este texto.

Os demais docentes, com outras qualificações além da Graduação, portavam certificados de Cursos denominados "lato-sensu"; a maioria restrito à carga horária mínima de 360 horas, seja como Aperfeiçoamento, ou Especialização; estes, categorizados como pós-graduação sem tese, compunham $31,5 \%$.

Desse modo, vale ressaltar que $56 \%$ dos docentes envolvidos como ensino superior de enfermagem, segundo o levantamento em 1974-1975, eram apenas graduados, embora entre os docentes-enfermeiros mesmo assim, mais de $30 \%$ eram classificados na carreira de magistério como titulares (18\%), adjuntos (13,4\%), e assistentes (23,4\%); assim, mais da metade, $54,8 \%$ tinham acesso à carreira, mesmo sem a qualificação pós-graduada no sentido estrito. $\mathrm{O}$ acesso se dava por tempo de Serviço e também isto poderia estar influenciando o não crescimento qualitativo desses cursos de enfermagem.

Para obter essas informações o GSS - DAU/MEC, já foi sendo ampliado, com a presença de mais uma enfermeira com Mestrado em Medicina Preventiva cursado no exterior, foi então dado início a um projeto de pesquisa e publicado em "Levantamento da Situação do Ensino Superior de Enfermagem no Brasil, 1975-1976"; este levantamento também contou com a 
participação de outras consultoras de enfermagem, além daquelas autoras do DocumentoBase, houve apoio de mais representantes de outras Universidades Federais (UFRGS, COPPE/ UFRJ, UFPe), a USP, e acrescidas da presença da então Presidente do COFEn e da Presidente da ABEn.

A preocupação com as questões qualitativas relativas ao diagnóstico de "menor crescimento do ensino de enfermagem" foi central para que desde o início da execução do plano, a Enfermagem, no GSS, abrisse frentes de trabalho.

Nesse sentido, as interfaces mais marcantes neste processo, foram:

- a busca de ampliar a participação da Comunidade de Enfermagem no Projeto, o que se fez com consultorias e assessorias de mais profissionais envolvidos com a educação de enfermagem, o que não se restringiu às representantes docentes de universidades, mas também e, imprescindivelmente, se fez com representantes de entidades organizativas pertinentes à categoria de enfermeiros, no caso, a participação da ABEn e do COFEn.

Para tanto, foi sendo ampliado um cadastro aberto a consultores de enfermagem cujo perfil ia além do envolvimento com a educação e a assistência, visto que integravam esse cadastro também como representantes de suas respectivas instituições e exerciam liderança nos cargos que ocupavam na categoria de enfermeiros. De modo geral, todas as consultoras tinham titulação e qualificação correspondentes, minimamente, ao grau de Mestras, obtidos em Cursos de Pós-Graduação, no País e/ou no exterior.

As atividades que realizavam na Consultoria, iam desde verificações "in-loco" Universidades Federais distribuidas em todo o pais, onde assessoravam os projetos individualizados dos Cursos, tendocomo referência de pauta, os requisitos mínimos de qualidade de Cursos, antes estudados e predefinidos como condição à abertura de qualquer um dos cursos em processo no GSS-DAU/MEC, naquela ocasião do Projeto de Enfermagem. Muitas vezes, se encarregavam de análise de dados do "Levantamento" que estava em andamento, outras, de participar na elaboração de estudos e documentos. O prestimoso e competente serviço prestado através de consultorias e assessorias, foi uma força coletiva, da maior importância, em solidariedade, para o acompanhamento durante o andamento deste projeto de implantação dos novos cursos de enfermagem em Universidades Federais - na década de 70.

Em meio a esse trabalho de consultorias fomos descobrindo que a despeito de ser recente o currículo vigente para o Ensino de Enfermagem, seria importante um novo estudo de proposta curricular de graduação em Enfermagem. O Par. 163/72 incluia habilitações específicas e na prática, muitas ambigüidades, provenientes da retirada da S. Pública, do corpo de disciplinas obrigatórias, além de outras dificuldades, que já vinham sendo sentidas pelas Escolas, sobremodo as implicações para os currículos desses novos cursos.

Foram convidadas as enfermeiras das mais experientes e peritas em Especializações, para opinar discutindo essa temática. Desta feita, foram as enfermeiras da UFBa as convidadas para esse trabalho. O ponto de vista era de que a ESPECIALIZAÇÃO na modalidade de RESIDÊNCIA DE ENFERMAGEM, na experiência das consultoras, definia uma pós-graduação no "sentido amplo", àquela época, oportuna, principalmente, para os recém-graduados em Enfermagem. Esta posição era diferente da habilitação especifica como complementar à graduação.

Uma discussão dessa envergadura, ratificava a necessidade de rever o Currículo relativo ao Parecer 163/72, principalmente em suas habilitações específicas, entendidas como diversificações da formação, e outras implicações trazidas para as práticas.

Estas considerações impulsionavam caminhada para criar mais uma importante interface das discussões internalizadas do Projeto Cursos Novos no GSS-DAU/MEC com a Comunidade de Enfermagem, principalmente os debates intelectuais da categoria profissional, como esse das teorizações curriculares, em suas várias articulações temáticas. Mais que grupo de teorizações, essa interface com os encaminhamentos decisórios do Projeto de Enfermagem, 
poderia estar politicamente mais revigorado, tanto dentro do MEC, com representações ampliadas, como diante da Comunidade de Enfermagem; foi então encaminhada a solicitação da Enfermagem ao GSS e do seu Coordenador ao Diretor do DAU/MEC, sobre a composição de uma Comissão de Especialistas do Ensino de Enfermagem (CEEEnfermagem) em 1978 e, esta solicitação, foi defendida junto ao Ministro que a tornou efetivamente composta. Tal CEEEnfermagem compunha-se de representantes de Universidades Federais e da USP, buscando a diversidade de regiões do país e, a representação daABEn. Embora as pesquisas documentais feitas a fim de elaborar o Aviso Ministerial que anunciava esta CEEEnfermagem, fizessem saber que em 1964, um Grupo de Trabalho vindo ao MEC para prestar consultoria chegasse a iniciar cálculos de "deficits" de recursos humanos de Enfermagem interrompeu seus trabalhos, mas, também foi categorizado como CEEEnfermagem. Logo, essa re-criação da CEEEnfermagem, nos anos 70 com representantes da Enfermagem (UFRGS, UFBa, UFRJ, USP e da ABEn) passou a elaborar seu diferenciado projeto de atividades e foi prestigiado $e$ prestigiou os estudos de educação da enfermagem, no DAU/MEC, e com a articulação da ABEn.

Uma de suas primeiras atividades (correlatas às demais Comissões de Especialistas no GSS/DAU/MEC), convergiu para o estudo de uma nova proposta curricular, e então, esta atividade tornou-se prioritária na CEEEnfermagem, a qual foi presidida pela então Presidente da ABEn, indicada a assumir a presidência por seus pares, nesta Comissão de Especialistas.

Os estudos curriculares da CEEEnfermagem tinham base em várias informações coletadas de outras Comissões de Currículo, existentes nas organizações internas das várias Escolas de Enfermagem, cujas Universidades estavam ali representadas, bem como por algumas indicações da Comissão de Educação da ABEn e mais, pelos avançados resultados do Projeto Novas Metodologias que se desenvolvia no Currículo de Enfermagem da Escola Ana Neri - UFRJ, único desenvolvido no então chamado Ciclo Profissional, dentre as demais Universidades que integravam esse Projeto Curricular coordenado pelo DAU/MEC, do ponto de vista administrativofinanceiro.

Vale lembrar o estusiasmo e a abnegação dessa CEEEnfermagem, bem como a efervescência de seus debates, o compromisso com a democratização, qualificação, e adequação curricular, ao lado da produção científica que com esse estudo, estava sendo construída. A diversidade de contribuições intelectuais à nova composição curricular redundou numa proposta definida pela transversalidade da educação. Assim, em qualquer das terminalidades parciais por semestre, o aluno se percebia e era percebido como um educador de saúde, com centralidade em alguma, das variações específicas do conjunto de disciplinas atributivas do domínio do seu saber-fazer, com criticidade e pertinência às possibilidades qualitativas de transformação, pela democratização, em saúde.

Para exemplificar, um dos semestres curriculares era, predominantemente, marcado pela experiência de aprender pesquisa. Assim, o aluno teria disponibilizado esse instrumento para a construção do conhecimento e talvez, essa inovação significasse, à época, um dos grandes saltos qualitativos dessa nova proposta curricular apresentada.

Marcamos, finalmente, um Seminário, ocasião em que o MEC/DAU através da CEEEnfermagem, apresentaria e abriria discussão do aludido estudo de proposta curricular, passo importante antes de enviá-la ao CFE. Ali, um grupo de docentes enfermeiros ofereceu uma resistência radical à esse estudo de mudança curricular, inclusive saindo em defesa do Par. 163/72, como um currículo ainda novo (em vigor há apenas 5 anos) e outras alegações tais como a de que a proposta era fora da realidade pois as docentes enfermeiras não estavam preparadas para ensinar pesquisa. Este foi um recuo necessário do GSS e mesmo da CEEEnfermagem para dar lugar aos avanços que não tardaram a chegar, nos anos 80 .

$\mathrm{Na}$ verdade, a elaboração curricular previa que, a cada semestre, o estudante de Enfermagem adquirisse uma determinada competência crítico-criativa e qualificada; ora em 
assistência direta a clientes, outras vezes em assistência a pessoas saudáveis, outra em pesquisa de enfermagem, outra em orientação e consultoria a grupos, etc. Respeitando esse momento de não compreensão do que se apresentava e certos de que, mais tarde, a crítica ao Par.163/72 haveria de chegar ganhando legitimação, restou a retirada do Projeto Curricular, em respeito à manifestação da própria Enfermagem.

O Grupo Setorial de Saúde, prosseguiu com aquilo que foi mais marcante no trabalho de Enfermagem ou seja, a criação de novos cursos. As quase quarenta Escolas juntas, no Brasil, formavam 600 enfermeiros por ano, uma turma de 15 enfermeiros por Escola, em média. Esse número de enfermeiros por ano, poderia ser, minimamente, dobrado.

A partir do momento em que foram constituídas as primeiras células de receptividade das Universidades Federais à organização desses Cursos, a presença de enfermeiras constituiase o requisito fundamental ao prosseguimento das negociações. Nem sempre, se dispunha desse tipo de profissional e esse foi um dos maiores desafios. As Universidades Federais receptivas ao novo curso, buscavam localizar enfermeiras a serem contratadas em tempo integral. Embora a maioria das Escolas e Cursos de Graduação em Enfermagem já existentes, tivesse o seu Corpo Docente constituído de enfermeiras, tão somente graduadas o mínimo de qualidade para a proposta desses novos cursos era a exigência de uma Especialização e a condição de que os nomes dessas enfermeiras especialistas, como novos docentes, fossem incluídos no Plano Institucional de Capacitação Docente, visando sua formação em Mestras e mais futuramente, em Doutoras. Nada se fez com facilidade, pois as ofertas de cursos de pósgraduação em Enfermagem eram escassas e não era comum que cursos de outras áreas pósgraduadas, aceitassem como alunas, as enfermeiras. Entretanto, a implantação de novos cursos não podia abrir mão deste requisito de qualidade docente. Como não havia nem docentes disponiveis nem mesmo tanta facilidade de encontrar enfermeiras com a pós-graduação, o assunto merecia uma discussão a partir de questionamento que fosse além de resolução exclusiva daquele momento e situação. Na pauta dos interesses da Enfermagem, no âmbito do Grupo Setorial de Saúde, ficou decidido, após debates sobre a questão, que havia necessidade de abertura do espaço de Pós-Graduação de Enfermagem na CAPES, não só nesse episódio, diante dos novos Cursos nas Universidades Federais, mas um espaço consolidado e, não somente de consultorias eventuais, mas um espaço de planejamento de pós-graduação. Especializações, Mestrados e Doutorados - ampliando assim a oportunidade de maior capacitação e titulação aos Corpos Docentes de Cursos de Enfermagem nas Instituições de Ensino Superior - além de oportunizar enfermeiros assistenciais a esse tipo de preparação.

Foi elaborado um documento e enviado à CAPES expondo a situação diagnosticada e o Projeto do DAU/MEC quanto aos Cursos de Enfermagem em Universidades Federais. A partir da defesa da solicitação contida nesse documento, foi possivel encaminhar 3 (três) medidas, apoiadas pelo DAU/MEC - CAPES. A primeira, emergencial, liberava recursos para planejamento e execução de Curso de Especialização em Metodologias do Ensino e da Pesquisa na Assistência de Enfermagem. Tal curso, foi desenvolvido em caráter emergencial, teve como alunas, as enfermeiras que estavam entrando para compor os Corpos Docentes dos Cursos Novos. Esses cursos, desenvolveram-se por três vezes, em acordo com a UFRJ e a CAPES, exclusivamente com essa finalidade, e dele participaram enfermeiras que seriam as novas docentes, em cursos novos distribuídos em todo o pais. Assim, realizou-se esse Curso, com o apoio e na Sede da ABEn - no Distrito Federal . O Corpo Docente, constituído de Doutores foi o mesmo Corpo Docente do Mestrado de Enfermagem da UFRJ; portanto, professores já credenciados, pela CAPES, para o ensino pós-graduado. A abordagem esteve centrada em Metodologia da Pesquisa, Metodologia do Ensino e Metodologia Assistencial.

A segunda medida conjunta DAU/MEC-CAPES, abria o espaço de participação da Enfermagem, constituindo representante de área, no âmbito das Comissões de Consultoria da CAPES, o que foi mais um contexto apropriado de discussão de pós-graduação, de bolsas de 
pesquisa, de bolsas de estudos no País e no Exterior, além de participações em avaliações, relatórios, planejamentos da pós-graduação, acompanhamentos de crescimento, apoio a eventos, e tudo mais que fosse pertinente a imprimir maior qualidade em avanços pós-graduados de Enfermagem. Isto implicava em atenção e acompanhamento dos PICDs que se propunham a incluir as novas docentes dos quadros desses novos Cursos, em Universidades Federais. L Ima das ocupações primeiras das pioneiras como representantes da área de Enfermagem da CAPES, foi fazer publicação sobre Pós-Graduação em Enfermagem, divulgada em 1978.

A terceira medida foi tomada com a decisão da categoria, (após muitos debates, receios de algumas lideranças profissionais e resistências internas) a de ampliar a oferta de Cursos de Mestrados e Doutorados, à época, muito restrita, concentrada também na região Sudeste, e, um outro Curso, organizando-se em consórcio entre Universidades na região Sul, entre 1974 e 1975 ( Scarduelli et al., 1997).

Embora a CAPES fosse um órgão vinculado ao DAU/MEC, a enfermagem antes desses anos 70 , ainda não tinha feito um acesso direto a esse órgão, ao lado de seus pares. À medida em que a CAPES tinha algo especifico a tratar sobre a Enfermagem, um convite ou uma consulta esporádica era feita, não caracterizando uma consultoria continuada e mais distante ainda, uma representação como membro da Comissão de Consultores em Saúde.

Essas considerações ressaltam uma parte da intencionalidade de, aliar à propostas de criação de Cursos à busca de expressiva qualidade, não se atendo, de modo circunscrito, aos Cursos Novos, e sim, a uma nova fisionomia da profissão, no que diz respeito à sua formação acadêmica, diante de um quadro cumulativo real e desvantajoso, do ensino de graduação em enfermagem em todo o País, divulgado nas estatísticas oficiais.

O itinerário mostra que esta luta não foi a luta de poucos e muito menos, uma luta solitária, daqueles que se incorporam ao trabalho cotidiano no DAU/MEC, mas um capitulo da história que se inspirou nas idéias das Consultoras "Três Marias", para fazer surgir uma nova constelação de enfermeiras. Se assim foi, não se fez no atropelo, mas num trabalho em que a presença da ABEn deu significado e houve o envolvimento de mais de 300 educadoras de enfermagem de todo o País, fortalecendo o andamento das ações. É justo referir também que o ânimo movido neste Projeto de Cursos Novos, trazia consigo a revitalização da esperança de que haveria um tempo depois dele, em que a participação da enfermagem já não seria a mesma, cresceria e continuaria respeitada em suas novas colocações, com autonomia em suas manifestações políticas e suas explicitações enquanto prática social. Esse ânimo não foi em vão. Não se tratava somente de uma mudança isolada da formação acadêmica nesta profissão, mas de uma resposta que se situava no cenário dos anseios de participação que toda a população brasileira estava decididamente buscando retomar, após longos períodos de amordaçamento da liberdade de todos os segmentos sociais. Com o maior número de enfermeiros recém graduados desses novos cursos muitos dos seus docentes filiaram-se como sócios da ABEn, a partir do final dos anos 70, justamente quando estavam sendo plantadas "as mudas", que seriam os canteiros moventes de uma Participação como nova expressão política também na ABEn. Em 1979, o ensaio geral da ABEn se fez, no Congresso Brasileiro de Enfermagem em Fortaleza - Ceará. Orquestrava-se em tênue batuta, o ritmo ainda espontâneo, mas cadente, daquilo que viria a ser o Movimento Participação, numa $A B E n$ que reunida nas areias do Ceará já entoava as canções dos caminhos da libertação. Por certo, a ABEn passou a contar com aproximadamente, mais 500 enfermeiros por ano, formados pelos "Cursos Novos", e, com certeza, instalou-se uma nova constelação de enfermeiros, derramados na extensão do País, do Acre ao Rio Grande do Sul, exprimindo-se profissionalmente também, no Centro, representado pelos Estados de Mato Grosso e Goiás, sem faltar com a cobertura da interiorização, onde quer que houvesse uma Universidade Federal, sede desses Cursos Novos.

E o que restou deste Projeto? Qual a tecedura visivel nesta trajetória?

A partir deste Projeto de Enfermagem junto ao GSS/DAU/MEC, a área de formação de 
enfermeiros pode ser entendida em duas etapas, ANTES E DEPOIS DE 1975 - "Marco Três Marias".

- Seguramente, a presença dos Cursos Novos, povoados hoje por Mestras e Doutoras; na FUFAC, UFC, UFPa, UFES, UFSCar, UFPel, FURG, UFSM, UnB, UFMT, UFGo, UFPr, Escola de Alfenas; e mais outras que foram assessoradas pelo Grupo Setorial de Saúde, como UFPi, e, até mesmo a UFRJ, está em trocas de experiência e avaliação com o Projeto Novas Metodologias nas disciplinas Profissionais do Currículo de Enfermagem.

- A continuidade de presença da CEEEnfermagem, renovados os seus membros com a articulação da ABEn.

- A iniciação do espaço da área de Enfermagem na CAPES (documento sobre PósGraduação na Área de Enfermagem - publicação de 1977).

- Documento sobre critérios Mínimos de Qualidade para autorização, funcionamento e reconhecimento de cursos de graduação na área de Enfermagem (elaborado a partir de um encontro de Coordenadores de Cursos de Enfermagem, 1976).

- A iniciação de 120 docentes - enfermeiros em pós-graduação (Especialização em Metodologia do Ensino, e da Pesquisa na Assistência de Enfermagem).

- A majoritária participação do ensino público na Área de formação de enfermeiros (crescendo de 12 para 25 Cursos de Graduação em instituições de subordinação administrativafinanceira federal.

- A participação de enfermeiras entre os demais profissionais pesquisadores e técnicos de análise de projetos no CNPq.

- A iniciação de discussão coletiva sobre Linhas e Áreas de Pesquisa em Enfermagem. Doc. Avaliação e Perspectiva-1982 - CNPq/CAPES/ABEn (DAU/CAPES).

A evocação da memória, habitada por tantos grupos vivos e que constituem hoje, outras memórias, vêm percorrer novos cenários, desenham seus itinerários, entretecer a trama de suas histórias, hoje em 2001, passados já um quarto de século. Em múltiplos pontos desses grupos vivos foram sendo construídos sujeitos do conhecimento (todos que, de algum modo, se envolveram no Projeto) e agora, nos resta a mais humana das alegrias ao testemunhar a vida pululante dos iniciais cursos de graduação de enfermeiros, hoje ampliados em muitas pósgraduações, muitas interfaces com a vida associativa, muita participação em meio aos desafios que se apresentam na presente condição política e econômica.

Refaz-nos pensar no que foi escrito por Foucault "...as condições políticas e econômicas não são um véu ou um obstáculo para o sujeito do conhecimento e sim, aquilo através do qual se formam sujeitos de conhecimento e em conseqüência, as relações de verdade." (Foucault, 1983)

Finalmente, convido a todos a compartilhar uma verdade que resta irremovivel, e que permeou todo o ânimo do trabalho ora registrado. Qual seja a constituição deste espaço de formação de enfermeiros, nos anos 70 , tem bases tão concretas quanto emblemáticas; é o mesmo que desocultar.

\section{"DAS TRÊS MARIAS NASCEU UMA NOVA CONSTELAÇÃO DE ENFERMEIROS"}

As "Três Marias" refere-se às consultoras de Enfermagem, Professoras Maria Rosa de Souza Pinheiro (USP), Maria Dolores Lins de Andrade (UFRJ) e Maria Nilda de Andrade (UFPE).

ABSTRACT: The objective of this study is to revisit the period of time between 1975 and 1979, and, within it, the history of the implantation of nursing graduation courses in federal universities and in geo-educational districts. It presents the development of a project called Projeto de Enfermagem no 
Grupo Setorial de Saúde - (Nursing Project in Health) SESU/DAU/MEC (ministry of culture and education), and points out the social and political determinants of the, so planned, qualitative and quantitative development of the courses mentioned before. The research clarifies the proposal, process and accomplishments of the Superior Nursing Project of Education, which was predominantly private until 1974 and became predominantly public from 1976 on. Furthermore, it also indicates implications such as: the Commission of Nursing Education Specialists (CEEEnfermagem), which was linked to ABEn and was the first collective proposal of Areas and Lines of Research in Nursing (CNPq/CAPES/ DAU/ABEn); as well as the introduction of institutionalized study fields in the academic institutions.

KEYWORDS: history, nursing education, graduation

RESUMEN: El artículo tiene como objetivo revisitar los años 75-79 y con ellos la historia de la implantación de nuevos cursos de formación en Enfermería en las Universidades Federales y en Distritos Geo-educacionales que aún no ofrecian ese tipo de Curso. Se presenta la trayetoria del desarrollo del Proyecto de Enfermería en el Grupo Sectorial de la Salud (SESU-DAU/MEC). Se ponen de relieve las determinantes político-sociales para el aumento cantitativo y calitativo intencional de esos Cursos. Se aclaran la propuesta, el proceso y las realizaciones implicadas en el Proyecto Superior de Enfermería, que antes predominaba como enseñanza privada (hasta 1974) y pasó a enseñanza pública (1976). Además, apunta implicaciones tales como la Comisión de Especialistas de la Enseñanza de Enfermería (CEEEnfermería) articulada a la ABEn y la primera propuesta colectiva de Áreas y Líneas de Investigación en Enfermería (CNPq/CAPES/DAU/ABEn), así como la creación de espacios institucionalizados en esos organismos de formación.

PALABRAS CLAVE: historia, enseñanza de enfermería, graduación

\section{REFERÊNCIAS BLIOGRAFICAS}

AQUINO, Rubim Santos Leão et al. Sociedade brasileira: uma história através dos movimentossociais: da crise do escravismo ao apogeu do neoliberalismo. 2. ed. R. Janeiro: Record, 2000. 924 p.

CONSELHO NACIONAL DE DESENVOLVIMENTO CIENTÍFICO E TECNOLÓGICO. CNPq. Documento Avaliação e Perspectivas. Brasília, 1982.

COORDENAÇÃO DE AVALIAÇÃO E CONTROLE. DAU. Relatório Anual, 1976. Brasília, 1977.

DEPARTAMENTO DE DOCUMENTAÇÃO E DIVULGAÇÃO. MEC/DAU. Estudo sobre a formação $e$ utilização dos recursos humanos na área da saúde. Brasília, 1976.

Relatório Anual, 1977. Brasília, 1978.

FOUCAULT, Michel. La verdad y las formas juridicas. México: Encuadernación Técnica, 1983. p.32

MINISTÉRIO DE EDUCAÇÃO E CULTURA/DAU. Desenvolvimento do Ensino Superior de Enfermagem no Brasil. Brasilia: MEC, 1978.

NORA, Pierre. Entre memória e história. A problemática dos lugares. Projeto história de São Paulo, v. 10, dez. 1993. p. 9.

SAMUEL, Raphael. História local e história oral. Revista Brasileira de História, São Paulo, ANPUH, $\mathrm{n}$. 19, 1990. p.237.

SCARDUELLI, Paulo et al. A Enfermagem da Universidade Federal de Santa Catarina. Uma história em movimento. Florianópolis: Insular, 1997 